\title{
OPTIMIZATION OF A TIMBER HALL STRUCTURE
}

\author{
STOJAN KRAVANJA \& TOMAŽ ŽULA \\ Faculty of Civil Engineering, Transportation Engineering and Architecture, University of Maribor, Slovenia
}

\begin{abstract}
The paper deals with the optimization of a timber hall structure, designed from timber portal frames, which are connected to steel purlins, rails and façade columns. While the portal frames are made of the glued laminated timber with the rectangular cross-sections, purlins, rails and façade columns are designed from steel I sections. The portal frames are supported by concrete square pad foundations. The optimization of the hall structure is performed by the mixed-integer non-linear programming (MINLP). The optimization model of the hall structure is developed. The objective function defines the material costs of the structure. The objective function is subjected to structural analysis and dimensioning constraints, which are defined according to Eurocode standards. The Modified OuterApproximation/Equality-Relaxation algorithm (OA/ER) and the linked multi-level strategy are applied. With the optimization, the minimal material costs of the structure are obtained, the optimal number of glulam frames and steel members and all standard/discrete cross-sections. A numerical example at the end of the paper shows the efficiency of the proposed optimization approach.
\end{abstract}

Keywords: cost optimization, structural optimization, timber hall, glulam hall, timber structures, steel structures, mixed-integer non-linear programming, MINLP.

\section{INTRODUCTION}

As a result of significant advances in the field of optimization of timber structures, a number of different search techniques and efficient solution algorithms have been developed and successfully applied. For example, Topping and Robinson [1] illustrated how the technique of sequential linear programming can be used to the optimization of timber framed structures. Kaziolasa et al. [2] introduced the cost minimization of timber structural elements by means of genetic algorithms and simulated annealing. An economic design optimization of cross laminated timber plate with stiffening ribs was demonstrated by Stanić et al. [3] with the help of a gradient optimization. The contribution of Pech et al. [4] shows the optimization of glued laminated timber beams using metaheuristic algorithms. Jelušič and Kravanja [5] applied the mixed-integer non-linear programming to the optimization of a composite floor system, built up from a concrete slab and timber beams. Jelušič [6] also presented the parametric cost optimization of a double tapered glulam beam, performed by the mixed-integer non-linear programming.

This paper presents the optimization of a timber hall structure, designed from equal timber main portal frames, which are connected to steel purlins and rails. The façade columns are in addition constructed in the front and rear façades. While the main frames are made of the glued laminated timber with the rectangular cross-sections, purlins, rails and façade columns are designed from steel I sections. Columns of the portal frames are supported by concrete pad foundations. This research represents a continuation to our former work of the optimization of single-storey steel buildings [7]-[9].

The optimization of timber hall comprises the optimization of the structure's material costs, which also includes the optimization of a number of the main frames, purlins, rails and façade columns. The optimal cross-sections of timber columns and beams of the main portal frames as well as the optimal steel sections of steel elements should also be obtained.

This simultaneous cost, topology and sizing optimization of the hall structure is a combined discrete and continuous type of optimization. It is proposed to be calculated with 
the mixed-integer non-linear programming, MINLP. The MINLP requires the development of the optimization model of the structure. It handles discrete and binary variables. The discrete variables are used for the calculation of the structure topology, the rounded dimensions of timber sections and square pad foundations, and for choosing the standard I sections of steel elements. The continuous variables are employed to determine the structure costs, loads, loadings, resistances, stresses and deflections. In the MINLP optimization model, the objective function of the material costs of the structure is subjected to (in)equality constraints of the design, resistance and deflection requirements for structural elements. The objective function comprises the material costs of the glued laminated timber for portal frames, the prices of steel I sections for steel elements and the prices of concrete for the foundations. The design, resistance and deflection constraints are defined in accordance with Eurocode 2 for concrete structure [10], Eurocode 3 for steel structure [11] and Eurocode 5 for timber structure [12].

The defined MINLP optimization problem is solved with the Modified OuterApproximation/Equality-Relaxation algorithm (OA/ER) by Kravanja and Grossmann [13], which was adapted for solving engineering structures [14], [15]. Since the combinatorics of the discrete optimization problem is relatively high, the linked multi-level strategy [16] is applied to accelerate the convergence of the algorithm.

\section{TIMBER HALL STRUCTURE}

The structure of the timber hall is consisted of several equal timber portal frames, which are mutually connected with steel purlins and rails (Fig. 1). The timber portal frames are made of glued laminated timber columns and pitched beams of rectangular cross-sections. Since the frames are made of timber and thus have no fully rigid connections, in calculations they are treated as sway frames. The columns are supported by square pad foundations. While purlins and rails are made of hot rolled steel IPE sections, the façade columns are designed from HEA sections. Steel members support the roof and façade claddings.

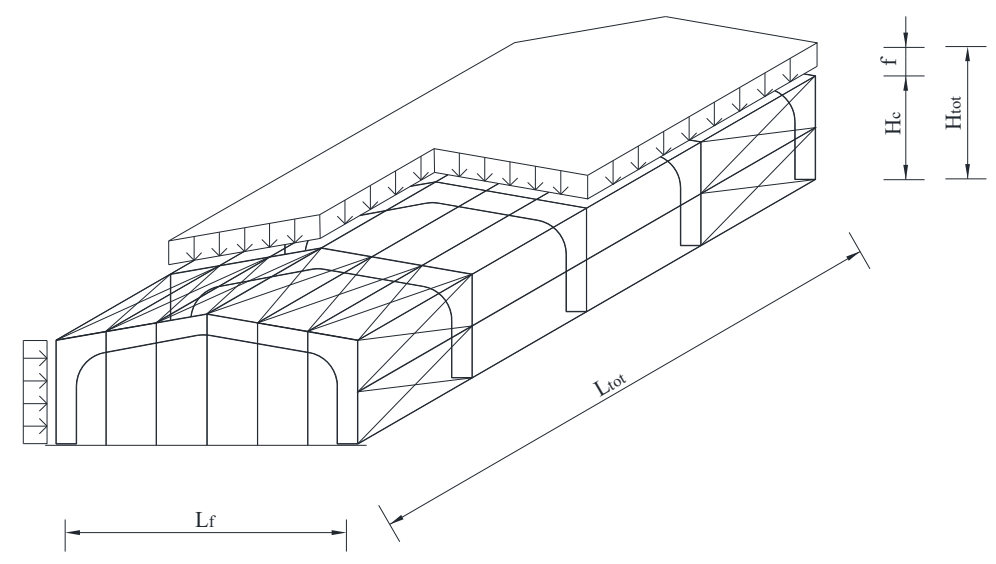

Figure 1: Timber hall structure.

The timber frame structure is subjected to permanent load $g$ and variable load $q$. The permanent load comprises the self-weight of structure $g$, the weight of the roof and the weight of the façade cladding. The variable load includes the uniformly distributed loads of snow $s$ 
wind $w$. The design load on the frame is calculated as a combination of the mentioned actions according to eqn (1)

$$
q_{E d}=\gamma_{g} \cdot g+\gamma_{q} \cdot s+\gamma_{g} \cdot \psi_{0} \cdot w
$$

where $\gamma_{\mathrm{g}}$ represents a partial factor for permanent actions ( 1.35 for ultimate limit state and 1.0 for serviceability state), $\gamma_{\mathrm{q}}$ stands for a partial factor for variable actions ( 1.50 for ultimate limit state and 1.0 for serviceability state) and $\psi_{0}$ is a factor for the frequent value of a variable action ( 0.6 for snow). The portal frame is also subjected to a horizontal wind $w$ hor, which as a concentrated force acts on the frame. All actions on the structural elements are in the optimization process automatically calculated taking into account the obtained distances between the elements.

Dimensioning equations of the glued laminated timber portal frame are defined in accordance to Eurocode 5. These equations comprise the cross-sections' resistances of columns and beams for axial compression force, bending moment, shear force and for the combined effect of compression and bending.

In this way, the design compressive stress $\sigma_{C, 0, d}$ in the timber cross-sections must be smaller or equal to the design compressive strength $f_{C, 0, d}$ (eqns (2) and (3)). In eqn (3), $N_{E d}$ is the design axial compress force, $\mathrm{A}$ is the cross-section area, $k_{\text {mod }}$ represents a modification factor taking into account the effect of the duration of load and moisture content, $f_{c, 0 \mathrm{~g}, k}$ stands for a characteristics compressive strength of glued laminated timber and $\gamma_{M}$ is a partial factor for material properties

$$
\begin{gathered}
\sigma_{C, 0, d} \leq f_{C, 0, d}, \\
\frac{N_{E d}}{A} \leq k_{\text {mod }} \cdot \frac{f_{C, 0, k}}{\gamma_{M}} .
\end{gathered}
$$

The design bending stress about y axis $\sigma_{m, y, d}$ should be smaller or equal to the design bending strength $f_{m, y, d}$ (eqns (4) and (5)). $M_{y, E d}$ is the design bending moment about y axis, $W_{y}$ is the section modulus about y axis and $f_{m, g, k}$ is a characteristics bending strength of glued laminated timber

$$
\begin{gathered}
\sigma_{m, y, d} \leq f_{m, y, d}, \\
\frac{M_{y, E d}}{W_{y}} \leq k_{m o d} \cdot \frac{f_{m, g, k}}{\gamma_{M}} .
\end{gathered}
$$

The design shear stress $\tau_{d}$ has be equal or smaller than the design shear strength $f_{V, d}$ (eqns (6)-(8)) where $V_{E d}$ is the design shear force, $b$ and $h$ stand for width and height/depth of the cross-section, $f_{v, g, k}$ represents a characteristics shear strength of glued laminated timber and $k_{c r}$ denotes a factor which takes into account cracking of the timber

$$
\begin{aligned}
\tau_{d} & \leq f_{V, d}, \\
\frac{3}{2} \cdot \frac{V_{E d}}{b_{e f} \cdot h} & \leq k_{\text {mod }} \cdot \frac{f_{v, g, k}}{\gamma_{M}}, \\
b_{e f} & =k_{c r} \cdot b .
\end{aligned}
$$

The combined effect of axial compression and bending is checked according to eqn (9), where $k_{m}$ is a factor which makes allowance for re-distribution of stresses and the effect of inhomogeneities of the material in a cross-section 


$$
\left(\frac{N_{E d} / A}{f_{C, 0, d}}\right)^{2}+k_{m} \cdot \frac{M_{y, E d} / W_{y}}{f_{m, y, d}} \leq 1.0 .
$$

Columns and beams of the portal frames are also checked for the compress buckling resistance, lateral torsional stability and for the combined effect of compress buckling and lateral torsion. The compress buckling resistance of the elements is checked twice: for the buckling about y axis (in the frame plane) and for the buckling about $\mathrm{z}$ axis. See eqns (10) and (11), where $k_{c}$ is an instability factor

$$
\begin{gathered}
\sigma_{C, 0, d} \leq k_{c} \cdot f_{C, 0, d}, \\
\frac{N_{E d}}{A} \leq k_{c} \cdot k_{\text {mod }} \cdot \frac{f_{c, 0 g, k}}{\gamma_{M}} .
\end{gathered}
$$

The combined effect between the compress buckling and bending is defined by eqns (12) and (13). While eqn (12) comprises the compress buckling about y axis, eqn (13) includes buckling about $\mathrm{z}$ axis

$$
\begin{gathered}
\frac{N_{E d} / A}{k_{c, y} \cdot f_{C, 0, d}}+k_{m} \cdot \frac{M_{y, E d} / W_{y}}{f_{m, y, d}} \leq 1.0, \\
\frac{N_{E d} /_{A}}{k_{c, z} \cdot f_{C, 0, d}}+k_{m} \cdot \frac{M_{y, E d} / W_{y}}{f_{m, y, d}} \leq 1.0 .
\end{gathered}
$$

Lateral torsional stability is checked by eqns (14) and (15), where $k_{\text {crit }}$ is a factor which takes into account the reduction bending strength due to lateral buckling

$$
\begin{gathered}
\sigma_{m, y, d} \leq k_{c r i t} \cdot f_{m, y, d}, \\
\frac{M_{y, E d}}{W_{y}} \leq k_{c r i t} \cdot k_{m o d} \cdot \frac{f_{m, g, k}}{\gamma_{M}} .
\end{gathered}
$$

The combined effect between the compress buckling and the lateral torsional buckling is defined by eqns (16) and (17). Eqn (16) defines the combination with the compress buckling about $\mathrm{y}$ axis and eqn (17) includes buckling about $\mathrm{z}$ axis

$$
\begin{gathered}
\frac{N_{E d} / A}{k_{c, y} \cdot f_{C, 0, d}}+\left(\frac{{ }^{M_{y, E d}} / W_{y}}{k_{c r i t} \cdot f_{m, y}}\right)^{2} \leq 1.0, \\
\frac{N_{E d} /_{A}}{k_{c, z} \cdot f_{C, 0, d}}+\left(\frac{M_{y, E d} / W_{y}}{k_{c r i t} \cdot f_{m, y, d}}\right)^{2} \leq 1.0 .
\end{gathered}
$$

In the apex zone, checked are the bending stresses $\sigma_{m, d}$ and the greatest tensile stresses $\sigma_{t, 90, d}$ perpendicular to the grain. The bending stresses are calculated according to eqn (18) and (19). While factor $k_{\ell}$ is dependent on the angle, depth and radius in the apex zone, factor $k_{r}$ takes into account the strength reduction due to bending of the laminates during production

$$
\begin{gathered}
\sigma_{m, d} \leq f_{m, d}, \\
k_{l} \cdot \frac{M_{a p, d}}{W_{a p}} \leq k_{r} \cdot k_{m o d} \cdot \frac{f_{m, g, k}}{\gamma_{M}} .
\end{gathered}
$$


The greatest tensile stresses $\sigma_{t, 90, d}$ perpendicular to the grain due to bending are checked by eqns (20) and (21), $k_{p}$ is factor which takes into account the effect of the stress distribution in the apex zone (is dependent on angle, depth and radius in the apex zone), $k_{d i s}$ is 1.7 for pitched chambered beams and $k_{v o l}$ is a volume factor, $f_{t, 90, d}$ is the design tensile strength perpendicular to the grain and $f_{t, 90, g, k}$, characteristics tensile strength perpendicular to the grain, $M_{a p, d}$ is a design moment at apex zone and $W_{a p}$ is a section modulus of the apex zone

$$
\begin{gathered}
\sigma_{t, 90, d} \leq k_{d i s} \cdot k_{v o l} \cdot f_{t, 90, d}, \\
k_{p} \cdot \frac{M_{a p, d}}{W_{a p}} \leq k_{d i s} \cdot k_{v o l} \cdot k_{\text {mod }} \cdot \frac{f_{t, 90, g, k}}{\gamma_{M}} .
\end{gathered}
$$

The combined shear and tension perpendicular to grain is also checked (eqn (22))

$$
\frac{\tau_{d}}{f_{v, d}}+\frac{\sigma_{t, 90, d}}{k_{d i s} \cdot k_{v o l} \cdot f_{t, 90, d}} \leq 1.0 \text {. }
$$

Steel purlins, façade rails and façade columns are checked for axial resistance (eqn (23)), shear resistance (eqn (24)), bending resistance (eqn (25)) and the compression buckling resistance (eqn (26)), where $f_{y}$ represents the yield strength of steel, $\gamma_{M 0}$ stands for the resistance partial safety factor, $A_{v}$ is the effective shear area of the cross-section, $\chi$ denotes the reduction factor due to the flexural buckling and $\gamma_{M I}$ is the resistance partial safety coefficient

$$
\begin{gathered}
N_{E d} \leq \frac{A \cdot f_{y}}{\gamma_{M 0}}, \\
V_{E d} \leq A_{v} \cdot \frac{f_{y}}{\sqrt{3}} \cdot \frac{1}{\gamma_{M 0}}, \\
M_{E d} \leq \frac{W \cdot f_{y}}{\gamma_{M 0}}, \\
N_{E d} \leq \chi \frac{A \cdot f_{y}}{\gamma_{M 1}} .
\end{gathered}
$$

The combination between the compression and bending moment resistance of steel elements is checked by eqn (27)

$$
\frac{N_{E d}}{A \cdot f_{y} / \gamma_{M 0}}+\frac{M_{E d}}{W \cdot f_{y} / \gamma_{M 0}} \leq 1.0
$$

The combination between the buckling and the lateral-torsional buckling resistance of steel members is defined by eqn (28), where $\chi_{L T}$ represents the reduction factor due to the lateral-torsional buckling

$$
\frac{N_{E d}}{\chi \cdot A \cdot f_{y} / \gamma_{M 1}}+\frac{M_{E d}}{\chi_{L T} \cdot W \cdot f_{y} / \gamma_{M 1}} \leq 1.0
$$

The bearing resistance in the ground under the reinforced concrete pad foundations is checked by eqn (29), where $A_{f}$ and $W_{f}$ stand for the surface area and the section modulus of the foundation, respectively

$$
\sigma=\frac{N_{E d}}{A_{f}}+\frac{M_{E d}}{W_{f}} \leq 200 k P a
$$


Vertical deflections of timber and steel elements $\delta_{\max }$ subjected to the overall load and vertical deflections $\delta_{2}$ subjected to the snow are defined to be smaller than span/200 and span/250, respectively. Horizontal deflections of the frame $u$ are calculated to be smaller than the frame height $/ 150$.

\section{OPTIMIZATION}

The optimization of the timber hall structure is performed with mixed-integer non-linear programming, MINLP. It comprises the generation of an MINLP superstructure, the development of an MINLP optimization model and the solution to the defined MINLP problem.

The generation of the MINLP superstructure includes the definition of topological alternatives, i.e. sets of different structure elements, from which the optimal numbers of portal frames, purlins, rails and the façade columns can be calculated in the topology optimization process. The superstructure includes also different alternatives for rounding the cross-section dimensions of the timber and concrete elements, and different alternatives of I section for steel members.

The MINLP optimization model of the timber hall structure is modelled in GAMS (General Algebraic Modelling System) environment [17]. The model comprises input data (scalars and parameters), variables, the cost objective function and equality, and inequality constraints. While input data include a global geometry of the hall, strengths of used materials, material characteristics, cross-sectional characteristics and prices of timber, steel, and concrete, variables include loads, resistances, stresses, deflections, cross-sectional dimensions, steel I sections, and costs and masses of all members.

The objective function, which is subjected to (in)equality design and dimensioning constraints, defines the material costs of the structure including costs of glued laminated timber, steel (structural plus reinforcing steel) and concrete (eqn (30)). In the objective function, $V$ represents the volumes of the materials used, $\rho$ stands for a density of steel and $c$ denotes the prices for materials (for timber and concrete in $€ / \mathrm{m}^{3}$, for steel in $€ / \mathrm{kg}$ )

$$
\min z=V_{\text {timb }} \cdot c_{\text {timb }}+\left(V_{\text {steel }}+V_{\text {reinf }, \text { steel }}\right) \cdot \rho_{\text {steel }} \cdot c_{\text {steel }}+V_{\text {concr }} \cdot c_{\text {concr }} \text {. }
$$

Equality and inequality constraints represent dimensioning constraints, introduced in the former section, they define loads, internal forces, deflections, costs and masses of the timber portal frames and steel members. The constraints comprise also equations for the calculation of the optimal number of portal frames, purlins, rails and façade columns, they include equations for choosing the optimal IPE and HEA sections of steel members and the equations for rounding the dimensions of the timber cross-sections and pad foundations.

To each member of the hall structure, an extra binary 0-1 variable $(y)$ is assigned. The element is selected if its binary variable takes value one $(y=1)$, otherwise it is removed from the superstructure $(y=0)$. For example, in order to obtain the optimal topology of the structure, a set of $i, i \in I$, alternative portal frames and their binary variables $y_{i, f r a m e}$ are defined. The optimal number of portal frames $N_{\text {frame }}$ is in the topology optimization calculated as the sum of binary variables $y_{i, f r a m e}$, assigned to the frame alternatives (eqn (31)). The optimal numbers of other elements (purlins, rails and façade columns) are calculated in the same way

$$
N_{\text {frame }}=\sum_{i \in I} y_{i, \text { frame }} \text {. }
$$

Optimal steel I sections are calculated in the simultaneous standard dimension optimization. For example, a set of $j, j \in J$, alternative hot rolled IPE sections $A_{j, p u r}$ to the purlin is defined. To each different IPE section alternative, a special binary variable $y_{j, p u r}$ is 
assigned. The optimal cross-section area of the purlin $A_{p u r}$ is determined as a scalar product between a vector of $j$ standard cross-section area alternatives $\mathbf{q}_{j, p u r}=\left\{A_{1, p u r}, A_{2, p u r}, A_{3, p u r}, \ldots, A_{j, p u r}\right\}$ and a vector of $j$ associated binary variables $\mathbf{y}_{j, \text { pur }}=\left\{y_{1, \text { pur }}, y_{2, \text { pur }}, y_{3, \text { pur }}, \ldots, y_{j, \text { pur }}\right\}$ (eqn (32)). Only one standard cross-section area is assigned to the purlin, because the sum of binary variables has to be equal to 1 (eqn (33)). In a similar way, the optimal standard I sections of other steel elements and the optimal rounded dimensions of timber and concrete cross-sections are calculated

$$
\begin{gathered}
A_{\text {pur }}=\sum_{j \in J} q_{j, p u r} y_{j, p u r}, \\
\sum_{j \in J} y_{j, p u r}=1 .
\end{gathered}
$$

The defined MINLP optimization problem is solved with the Modified OuterApproximation/Equality-Relaxation algorithm, which includes a global convexity test. Since the combinatorics of the discrete optimization problem is relatively high, the linked multilevel strategy is applied to accelerate the convergence of the algorithm. The strategy starts with the continuous optimization of the structure (the non-linear programming), which represents a good starting point for the discrete optimization of the structural topology and standard/discrete cross-sections.

\section{NUMERICAL EXAMPLE}

The paper presents the cost optimization of a $60 \mathrm{~m}$ long, $6.3 \mathrm{~m}$ high and $15 \mathrm{~m}$ wide (span) timber hall structure. While the main portal frames are designed from glued laminated timber GL36h; purlins, rails and façade columns (in the front and rear façades) are made of hot rolled steel IPE sections from structural steel S 355 . The structure is subjected to the self-weight, snow $s=1.0 \mathrm{kN} / \mathrm{m}^{2}$ and horizontal wind $w=0.5 \mathrm{kN} / \mathrm{m}^{2}$. The task of the optimization is to calculate the optimal material costs of the structure, the optimal number of structure elements (timber frames and steel members) and all cross-sections (rounded timber and concrete crosssectional dimensions and steel IPE sections).

Besides the defined global geometry and loads, input data include characteristics strengths of glulam and steel, modules, densities, alternatives of the structure topology, IPE sections, discrete dimensions, prices of materials, like: $k_{\text {mod }}=0.9, \gamma_{M}=1.25, k_{m}=0.7, f_{c, 0 g, k}=31$ $\mathrm{MPa}, f_{m, g, k}=36 \mathrm{MPa}, f_{v, g, k}=4.3 \mathrm{MPa}, f_{t, 90, g, k}=0.6 \mathrm{MPa}, E_{0, g, 05}=11900 \mathrm{MPa}, f_{y}=355$ $\mathrm{MPa}, E=210000 \mathrm{MPa}$ (steel), $\rho_{\text {timb }}=540 \mathrm{~kg} / \mathrm{m}^{3}, \rho_{\text {steel }}=7850 \mathrm{~kg} / \mathrm{m}^{3}, \rho_{\text {concr }}=2500 \mathrm{~kg} / \mathrm{m}^{3}$, $c_{\text {timb }}=800 € / \mathrm{m}^{3}, c_{\text {steel }}=1 € / \mathrm{kg}, c_{\text {concr }}=100 € / \mathrm{m}^{3}$, etc.

The superstructure comprises 70 portal frames, 50 purlins, 20 rails, 18 different IPE sections for purlins and rails separately, 24 different HEA sections for façade columns, 136 different discrete dimensions for the rectangular timber cross-sections (with the step of $2.5 \mathrm{~cm}$ for width and depth separately) and 122 different discrete dimensions for the square pad foundation (with the step of $2.5 \mathrm{~cm}$ ). The combinatorics of the defined discrete alternatives gives $4.9917 \cdot 10^{16}$ different structure alternatives. One is the optimal one.

The optimization model with all defined data is applied. The MINLP computer program MipSyn [18] is used for the MINLP optimization. The Modified OA/ER and the linked multilevel strategy are applied. GAMS/CONOPT (generalized reduced-gradient method) [19] is used for continuous optimization and GAMS/CPLEX (branch and bound) [20] is employed for the discrete optimization sub-problems.

The calculated optimal result represents the minimal structure's material costs of $52,411 €$ (the selling price is about four times higher) and the optimal topology of 10 glulam portal frame, 12 purlins, six rails and $(2 \times 11)$ façade columns in the front and rear façades 
(Fig. 2). The obtained optimal cross-sections include a glulam rectangular cross-section 200/1100 mm for columns and pitched beams of the main frames, IPE 200 for purlins and rails, HEA 160 for the façade columns and a square area of $1.625 \times 1.625 \mathrm{~m}^{2}$ for a single metre deep pad foundations (Fig. 3).

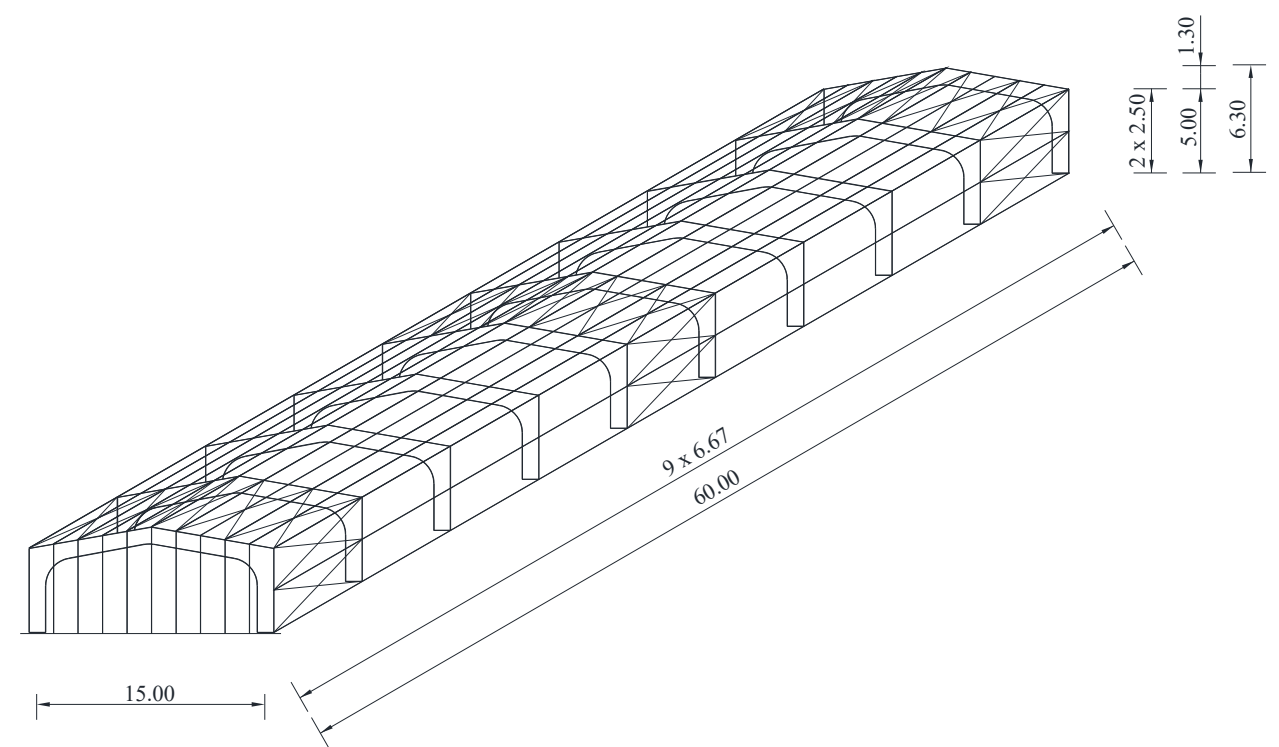

Figure 2: Optimal topology of the hall structure (metres).

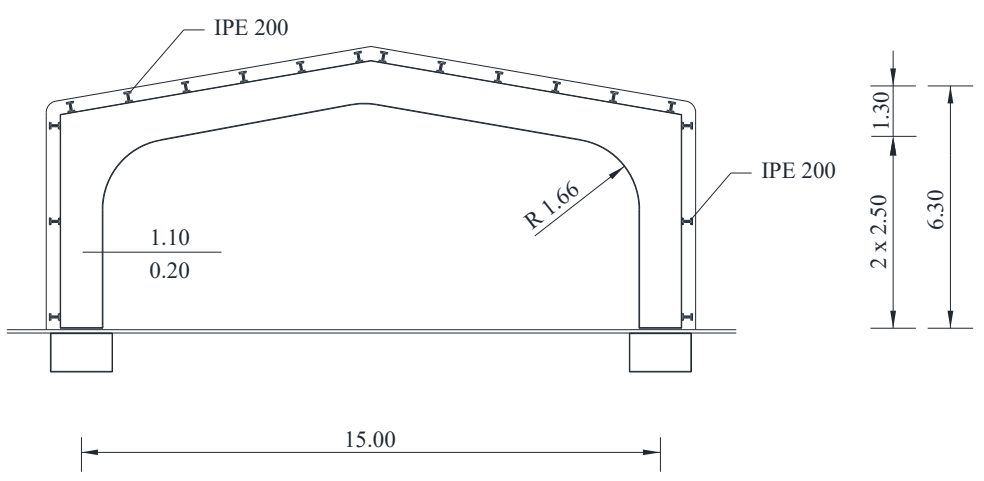

Figure 3: Optimal glulam and steel sections (metres).

\section{CONCLUSIONS}

The paper deals with the optimization of a hall structure, designed from timber portal frames, which are connected to steel purlins, rails and façade columns. The later are constructed in the front and rear façades. While the portal frames are made of the glued laminated timber with the rectangular cross-sections, purlins, rails and façade columns are designed from steel I sections. The portal frames are supported by concrete pad foundations. The optimization of 
the mixed glulam-steel structure is performed by the mixed-integer non-linear programming, MINLP. The optimization model is developed. The objective function defines the material costs of the structure. The objective function is subjected to structural analysis and dimensioning constraints, which are defined according to Eurocode standards. The Modified Outer-Approximation/Equality-Relaxation algorithm (OA/ER) and the linked multi-level strategy are applied.

A numerical example at the end of the paper shows the efficiency of the proposed optimization approach. In a single optimization procedure obtained are the minimal material costs of the structure, the optimal number of glulam frames and steel members and all standard/discrete cross-sections.

\section{ACKNOWLEDGEMENT}

The authors are grateful for the support of funds from the Slovenian Research Agency (program P2-0129).

\section{REFERENCES}

[1] Topping, B.H.V. \& Robinson, D.J., Optimization of timber framed structures. Computers and Structures, 18(6), pp. 1167-1177, 1984.

[2] Kaziolasa, D.N., Bekasb, G.Ä., Zygomalasc, I. \& Stavroulakisd, G.E., Life cycle analysis and optimization of a timber building. 7th International Conference on Sustainability in Energy and Buildings, Energy Procedia, 83, pp. 41-49, 2015.

[3] Stanić, A., Hudobivnik, B. \& Brank, B., Economic-design optimization of cross laminated timber plates with ribs. Composite Structures, 154, pp. 527-537, 2016.

[4] Pech, S., Kandler, G., Lukacevic, M. \& Füssl, J., Metamodel assisted optimization of glued laminated timber beams by using metaheuristic algorithms. Engineering Applications of Artificial Intelligence, 79, pp. 129-141, 2019.

[5] Jelušič, P. \& Kravanja, S., Optimal design of timber-concrete composite floors based on the multi-parametric MINLP optimization. Composite Structures, 179, pp. 285293, 2017.

[6] Jelušič, P., Determining optimal designs of timber beams with non-uniform crosssection. WIT Transactions on the Built Environment, vol. 175, WIT Press: Southampton and Boston, pp. 169-175, 2018.

[7] Žula, T. \& Kravanja, S., The two-phase MINLP optimization of a single-storey industrial steel building. WIT transactions on the Built Environment, vol. 97, WIT Press: Southampton and Boston, pp. 439-448, 2008.

[8] Kravanja, S. \& Žula, T., Cost optimization of industrial steel building structures. Advances in Engineering Software, 41(3), pp. 442-450, 2010.

[9] Kravanja, S., Turkalj, G., Šilih, S. \& Žula, T., Optimal design of single-story steel building structures based on parametric MINLP optimization. Journal of Constructional Steel Research, 81, pp. 86-103, 2013.

[10] Eurocode 2, Design of concrete structures, European Committee for Standardization, Brussels, 2004.

[11] Eurocode 3, Design of steel structures, European Committee for Standardization, Brussels, 2005.

[12] Eurocode 5, Design of timber structures, European Committee for Standardization, Brussels, 2008.

[13] Kravanja, Z. \& Grossmann, I.E., New developments and capabilities in PROSYN: An automated topology and parameter process synthesizer. Computers Chem. Eng., 18, pp. 1097-1114, 1994. 
[14] Kravanja, S., Kravanja, Z. \& Bedenik, B.S., The MINLP optimization approach to structural synthesis. Part I: A general view on simultaneous topology and parameter optimization. Int. J. Numer. Methods Eng., 43, pp. 263-292, 1998.

[15] Kravanja, S., Kravanja, Z. \& Bedenik, B.S., The MINLP optimization approach to structural synthesis. Part II: Simultaneous topology, parameter and standard dimension optimization by the use of the linked two-phase MINLP strategy. Int. J. Numer. Methods Eng., 43, pp. 293-328, 1998.

[16] Kravanja, S., Soršak, A. \& Kravanja, Z., Efficient multilevel MINLP strategies for solving large combinatorial problems in engineering. Optim. Engng., 4, pp. 97-151, 2003.

[17] Brooke, A., Kendrick, D. \& Meeraus, A., GAMS: A User's Guide, Scientific Press: Redwood City, CA, 1988.

[18] Kravanja, Z., Challenges in sustainable integrated process synthesis and the capabilities of an MINLP process synthesizer MipSyn. Comput. Chem. Eng., 34(11), pp. 1831-1848, 2010.

[19] Drudd, A.S., CONOPT: A large-scale GRG code. ORSA Journal on Computing, 6, pp. 207-216, 1994.

[20] CPLEX User Notes, ILOG Inc. 